\title{
Mask Reuse in the COVID-19 Pandemic: Creating an Inexpensive and Scalable Ultraviolet System for Filtering Facepiece Respirator Decontamination
}

\author{
Rachel M. Gilbert, ${ }^{a}$ Michael J. Donzanti, ${ }^{a}$ Daniel J. Minahan, ${ }^{a}$ Jasmine Shirazi, ${ }^{a}$ Christine L. Hatem, \\ Brielle Hayward-Piatkovskyi, ${ }^{b}$ Allyson M. Dang, ${ }^{c}$ Katherine M. Nelson, ${ }^{d}$ Kimberly L. Bothi, ${ }^{a, e}$ \\ Jason P. Gleghorn ${ }^{a, b}$
}

\section{Key Messages}

- Ultraviolet germicidal irradiation (UVGI) systems can be used to decontaminate filtering facepiece respirators that are in short supply during the current COVID-19 pandemic, but are costly and scarce.

- Custom-built UVGI systems can be easily and affordably created using common items found in hardware stores and within research institutions.

- Health care workers and administrators should consider this setup as a cost-effective option to combat personal protective equipment (PPE) shortages during the current pandemic.

- Academic institutions should consider fostering collaborations with local health care institutions to provide idle resources to front line health care workers facing PPE shortages.

\footnotetext{
a Department of Biomedical Engineering, University of Delaware, Newark, DE, USA.

b Department of Biological Sciences, University of Delaware, Newark, DE, USA c Department of Chemistry and Biochemistry, University of Delaware, Newark, DE, USA.

d Department of Chemical and Biomolecular Engineering, University of Delaware, Newark, DE, USA

e Global Engineering, University of Delaware, Newark, DE, USA.

Correspondence to Jason Gleghorn (gleghorn@udel.edu).
}

\section{ABSTRACT}

As the current COVID-19 pandemic illustrates, not all hospitals and other patient care facilities are equipped with enough personal protective equipment to meet the demand in a crisis. Health care workers around the world use filtering facepiece respirators to protect themselves and their patients, yet during this global pandemic they are forced to reuse what are intended to be single-use masks. This poses a significant risk to these health care workers along with the people they are trying to protect. Ultraviolet germicidal irradiation (UVGI) has been validated previously as a method to effectively decontaminate these masks between use. However, not all facilities have access to the expensive commercial ultraviolet type C (UV-C) lamp decontamination equipment required for UVGI. UV-C bulbs are sitting idle in biosafety cabinets at universities and research facilities around the world that have been shuttered to slow the spread of COVID-19. These bulbs may also be available in existing medical centers where infectious diseases are commonly treated. We developed a method to modify existing light fixtures or create custom light fixtures that are compatible with new or existing UV-C bulbs. This system is scalable; can be created for less than US $\$ 50$, on site and at the point of need; and leverages resources that are currently untapped and sitting unused in public and private research facilities during the pandemic. The freely accessible design can be easily modified for use around the world. Health care facilities can obtain this potentially lifesaving UVGI resource with minimal funds by collaborating with research facilities to obtain the UV-C meters and UV-C bulbs if they are unavailable from other sources. Although mask reuse is not ideal, we must do what we can in emergency situations to protect our health care workers responding to the pandemic and the communities they serve.

\section{INTRODUCTION}

Tealth care workers (HCWs) are critical to the care 1 and treatment of individuals with the severe acute respiratory syndrome coronavirus 2 (SARS-CoV-2) or coronavirus disease known as COVID-19. In addition to the needed beds and ventilators, personal protective equipment (PPE), particularly filtering facepiece respirators (FFRs), are essential to ensure the health and safety 
of not only trained doctors, nurses, and emergency response personnel, but also other health care facility staff who play an important role in cleaning, disinfecting, and preparing spaces for patient care. Additionally, whereas much of the focus of HCW risk is on large hospitals and current hotspots that do not have access to FFRs, also called N95 masks in the United States, the spread of SARS-CoV-2 has also affected residential facilities and rural clinics around the globe. These communities face additional challenges with limited resources and larger logistical obstacles to obtain FFRs.

At the time of publication, shipping used FFRs to localized centers for hydrogen peroxide vapor (HPV, also written as $\mathrm{H}_{2} \mathrm{O}_{2}$ vapor) decontamination was only available in very limited locations in the United States. ${ }^{1-3}$ HPV decontamination is a U.S. Food \& Drug Administration-approved method for N95 mask decontamination, and manufacturing and deployment of these systems is currently underway. However, the operational and coordination challenges associated with even localized deployment of HPV centers for N95 decontamination are significant. This is evidenced by contemporary reports of HCWs being issued FFRs for continuous (re)use over week-long time periods. ${ }^{4-6}$ Even many months after this pandemic entered the global arena, many locations around the world and in the United States are still struggling to provide adequate PPE for HCWs and other staff at high risk. 7,8 Additionally, Nebraska Medicine has initiated a U.S. Centers for Disease Control and Prevention (CDC) approved on-site ultraviolet germicidal irradiation (UVGI) decontamination system for FFR mask decontamination. ${ }^{9}$ UVGI has been demonstrated to be effective at quickly decontaminating FFRs for viruses like the novel SARS-CoV-2 and for multiple cycles of decontamination. ${ }^{10-12}$ Whereas UVGI decontamination has important limitations as discussed herein, these methods currently are being deployed as emergency procedures during the SARS-CoV-2 pandemic. The Nebraska Medicine protocol uses an operating room UVGI decontamination system for FFR mask decontamination, a system that many smaller clinics, rural hospitals, and residential health care facilities may not have.

We document procedures to build a similar type of UVGI platform using off-the-shelf components from a hardware store and UV-C bulbs that can be obtained through online marketplaces or from biosafety cabinets (class I, II, or III) that are ubiquitously found throughout academic research and industrial centers around the world. This system is scalable; can be created for less than US $\$ 50$, on site and at the point of need; and leverages resources that are currently untapped and sitting unused in public and private research facilities that have shut down during the COVID-19 pandemic. Health care facilities can obtain this potentially lifesaving UVGI resource with minimal funds by collaborating with research facilities to obtain the UV-C meters and limited availability UV-C bulbs required for UVGI treatment.

\section{FFR DEMAND AND NEED DURING THE COVID-19 PANDEMIC}

The COVID-19 pandemic is expected to continue to increase the burden on health care providers. As the number of cases increase, health care facilities will continue to be stretched to their limits in terms of supplies and labor. There are 6,146 hospitals in the United States, 5,198 of which are classified as community hospitals; 209 are federal government hospitals, 616 are nonfederal psychiatric hospitals, and 123 other hospitals. ${ }^{13}$ Community hospitals are those that can be accessed by the general public, including short-term general and specialty hospitals, and are classified as rural or urban. There are 3,377 urban community hospitals that serve approximately 106,000 square miles (about $84 \%$ of the population), and there are 1,821 rural community hospitals that serve approximately 3.4 million square miles (about 16\% of the U.S. population). ${ }^{14}$ These numbers do not include urgent care centers, doctor's offices, and other non-hospital medical sites involved in the pandemic response.

In contrast, many low- and middle-income countries (LMICs) rely heavily on a limited number of fully resourced hospitals in urban centers with varying degrees of professional health care access in rural areas. Current data on health facilities is difficult to find in many LMICs; however, we can find examples of the resource constraints. For example, Kenya has 842 public and private hospitals serving more than 53 million people. ${ }^{15,16}$ Only 24 of these facilities are classified as county or national referral hospitals and large teaching or private hospitals. The remainder of Kenya's more than 11,000 health facilities include smaller clinics, dispensaries, health centers, maternity wards, and nursing homes, not to mention thousands of volunteer HCWs in rural communities. Due to limited supplies of PPE at these facilities, the Government of Kenya recently pleaded with the public to reserve N95 masks for the nation's HCWs because the entire population was required to wear face coverings in public. ${ }^{17}$

\author{
We built a UVGI \\ system to \\ decontaminate \\ FFRs for less than \\ US\$50 that is \\ easily made \\ on site, is scalable, \\ and uses \\ resources that are \\ unused.
}


There are currently dramatic shortfalls in protective equipment in countries with relatively robust health care services, like the United States, and these resources are even more precious in resource-limited communities where fewer doctors and nurses are serving larger populations. According to the World Health Organization ${ }^{18}$ :

Africa suffers more than $22 \%$ of the global burden of disease but has access to only $3 \%$ of HCWs, and less than $1 \%$ of the world's financial resources.

Losing a single doctor during this pandemic can have a detrimental impact on already strained health care systems across the continent. ${ }^{19}$ Even in the United States, rural clinics and hospitals serve patient populations sometimes across hundreds of miles, and in some areas, there is a single doctor for several thousand square miles. ${ }^{20}$ Ensuring HCWs around the world are protected as best as possible is not only ethical, but imperative.

Challenges exist for both urban and rural health care facilities globally. Although urban hospitals often have access to more resources due to the larger population they serve, they experience a strain on their resources during a pandemic precisely because of the significantly larger numbers of people they need to urgently treat. Conversely, rural clinics and health care facilities around the globe often have less funds to operate and face additional logistical challenges to provide patients access to care. Facilities cannot afford to have staff become ill and lead to a decrease in the number of HCWs to treat patients, and therefore need proper FFRs to protect themselves. Additionally, HCWs can potentially spread infection if they are not properly equipped with essential FFRs or if they are forced to reuse potentially contaminated masks. Many HCWs are currently facing the options of not wearing an essential mask, constructing makeshift FFRs with limited efficacy, or reusing a soiled mask - the majority are choosing the latter. ${ }^{8,21,22}$ There is an unprecedented worldwide shortage of lifesaving equipment that our HCWs need to continue serving their communities safely. In addition, essential personnel working in pharmaceuticals, dentistry, custodial services, delivery services, and law enforcement also require protection while they keep operations afloat. A global shortage of FFRs is expected to persevere due to supply chain challenges, especially for 1 essential component: the melt-blown polypropylene fabric material that filters infectious diseases like the SARS-CoV-2 during inhalation by the wearer. $^{23}$ As the virus continues to spread into both overburdened and underserved health care systems around the globe, already limited FFR supplies are in extremely short supply. Distributed systems for N95 decontamination are needed to keep up with demand.

The CDC estimated that a 42-day influenza outbreak in the United States, which represents just $4.25 \%$ of the global population, could require more than 90 million FFRs for HCWs alone. ${ }^{24}$ This would scale to almost 800 million FFRs in a year. A model of a hypothetical influenza pandemic predicted 1.7 to 7.3 billion respirators would be required if only $20 \%-30 \%$ of the U.S. population were to be infected. ${ }^{25}$ This does not account for non-HCWs, such as law enforcement officers and other essential personnel, who may require respiratory protection. Given the uncertain nature of this pandemic and demonstrated logistical challenges in obtaining adequate resources, it is reasonable to assume that need will far exceed the value given in this projection and that demand will only grow.

\section{FFR DECONTAMINATION AND REUSE}

FFRs are designed and manufactured for singleuse applications. Depending on the specific country, FFRs are named differently as masks with the following distinction as N95 (United States), FFP2 (Europe), KN95 (China), P2 (Australia/NZ), Korea $1^{\text {st }}$ class (Korea), or DS (Japan). There is slight variability to the mask filtering specification depending on government regulations, but these masks are all expected to function similarly. ${ }^{26}$ Each mask is composed of polypropylene fibers to create a physical barrier based on pore size and leverages the electrostatic charge of the material to improve filtering of aerosolized particles such as SARS-CoV-2 viral particles. The inability to scale FFR manufacturing at the rate needed to meet current demand during the COVID-19 pandemic has necessitated the reuse of N95 respirators among HCWs. Work has shown that pathogens such as viruses can contaminate and exist for extended periods of time on the outer surface of FFRs. ${ }^{27}$ Beyond the risk to HCWs in storing and reusing what is intended to be single-use PPE, other at-risk patients could be exposed to the virus when consulting with a HCW who is reusing their PPE that was previously used with a patient who is positive for COVID-19. It should be noted that repeated redonning FFRs alone poses serious risk to the user due to loss of strap elasticity, nose fit, and therefore, mask integrity. Due to need, redonning is already occurring, and these masks 
have the potential to be contaminated with viral particles, risking further spread of the virus.

The CDC has suggested a method of FFR reuse by issuing each HCW 5 FFRs. Upon completion of a shift, the FFR is placed in a paper bag and redonned after sitting in that bag for 5 days. $^{28}$ This time period was determined based on data that suggests that SARS-CoV-2 can exist on surfaces for as much as or longer than 72 hours. This allows a HCW to cycle through their own previously used masks; however, there are still a variety of problems with this method. Potentially contaminated masks must be stored for long periods of time, and often HCWs do not have the proper space to do this. Masks may also be heavily soiled or moist from the prolonged wear, which would preserve the virus for longer durations, and it has not been rigorously tested whether 5 days is enough time to decontaminate masks under these conditions. HCWs and other essential personnel are desperate for another solution to decontaminate masks effectively, cheaply, and more quickly.

Decontamination of FFRs must be considered carefully because improper decontamination can also give users a false sense of security in addition to compromising mask integrity. A variety of options have recently been developed to allow for decontamination between uses including HPV decontamination, UVGI treatment, and the applications of heat/humidity/washing. ${ }^{29}$ The recently established N95DECON website (https://www. n95decon.org) gives a summary of these methods, including current understandings and limitations to consider for each method. The U.S. Food $\delta$ Drug Administration approved hydrogen peroxidebased decontamination offered by a U.S. company, Battelle. Although it is a highly effective resource, the procedure relies on shipment of contaminated masks to Ohio, where the company is based, for decontamination $^{30,31}$ and/or the production of such HPV decontamination equipment for regional deployment. The ability for health care facilities and health workers to decontaminate their own masks in minutes, as opposed to days, is a great advantage of using UVGI.

Importantly, UVGI is listed by the CDC as an appropriate method of FFR decontamination and provides key considerations when using this method of decontamination. ${ }^{28}$ Successful implementation of UVGI in a hospital setting is already being used by Nebraska Medicine. 9 Unfortunately, their system requires 2 surgical suite UVGI towers, with each costing in excess of US\$20,000, which not all health care facilities have available.
Herein, we developed a UVGI lamp setup that provides the capability for health care facilities and local regional centers that do not have access to operating room UVGI towers to implement their own N95 mask decontamination system. These health care facilities can use our proposed lowtech UVGI lamp, along with the work flow developed by Nebraska Medicine, to decontaminate FFRs in their own centers. Our UVGI lamp is accessible, inexpensive, requires little expertise to construct and operate, and repurposes existing UV-C bulbs not currently in use. The system takes advantage of common parts available at any hardware store. Once implemented, this method allows for high throughput and quick decontamination cycles that should allow for safer redonning of FFRs.

\section{FFR DECONTAMINATION USING UVGI}

UVGI systems have been used throughout the health care industry to decontaminate work environments such as surgical suites, equipment, and ambulances. Single-stranded RNA (ssRNA) viruses, like SARS-CoV-2, are especially susceptible to UV decontamination. ${ }^{10}$ Previous work has shown that UVGI systems can also be used to decontaminate FFRs by reducing the viability of the influenza virus, also an ssRNA virus, by $3 \log .{ }^{11} \mathrm{~A}$ very recent small study has shown that UV is capable of decontaminating N95 mask fabric contaminated with SARS-CoV-2. ${ }^{32}$ There is variable effectiveness of UVGI depending on the mask manufacturer, the different materials of the mask (polypropylene filter versus rubber strap), and the medium in which the virus resides (in liquid, in air, on surface). UVGI decontamination also runs the risk of damaging the FFR materials, which can compromise the integrity of the mask and its usefulness in filtering particles and acting as an effective piece of PPE. However, a variety of studies have looked at the effect of UVGI on mask integrity, ${ }^{33,34}$ even with repeated exposure, ${ }^{12,29,35-37}$ and have found no significant increase in viral penetration, nor decrease in mask stability, even at UVGI doses $>10,000$ times the required dose to effectively reduce influenza infectivity. ${ }^{38}$ In other studies, 3 UVGI cycles of $1.6-2.0 \mathrm{~mW} / \mathrm{cm}^{2}$ for 15 minutes did not cause significant changes in respirator fit, ${ }^{35}$ and there was no change in filtration performance. However, using UVGI to decontaminate FFRs requires careful monitoring of UV dosage and the number of times a single mask is decontaminated to minimize damaging the

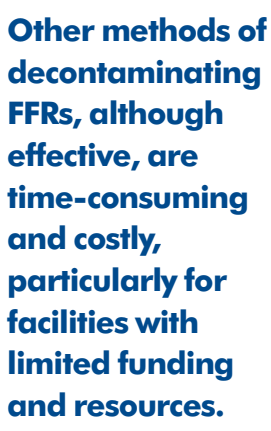


mask's integrity. The current literature related to UVGI decontamination of N95 masks, mainly in the context of influenza, is summarized (Table). Importantly, the CDC has approved the protocol from Nebraska Medicine for UVGI decontamination during the COVID-19 pandemic.

UVGI inactivates viruses by damaging their nucleic acids and, to a lesser extent, their protein

TABLE. Summary of Literature Using Ultraviolet Germicidal Irradiation for Filtering Face Respirators Decontamination

\begin{tabular}{|c|c|c|c|c|c|c|c|c|c|c|c|}
\hline First Author & Year & Dose & Time & Dose & Repeated & $\begin{array}{l}\text { Total } \\
\text { Accumulated } \\
\text { Dose }\end{array}$ & Distance & $\begin{array}{l}\text { Bulb } \\
\text { Specs }\end{array}$ & Effectiveness & $\begin{array}{l}\text { Room } \\
\text { Conditions }\end{array}$ & Fit/Degradation \\
\hline Tseng $^{10}$ & 2007 & & $5-255 \mathrm{sec}$ & $\begin{array}{l}2.51-6.50 \\
\mathrm{~mJ} / \mathrm{cm}^{2}\end{array}$ & $1 \times$ & $\begin{array}{l}2.51-6.50 \\
\mathrm{~mJ} / \mathrm{cm}^{2}\end{array}$ & $30.5 \mathrm{~cm}$ & $4 \times 8 W$ & $\begin{array}{l}\text { Kills } 99 \% \text {, } \\
\text { decreased } \\
\text { effectiveness at } \\
\text { higher humidity }\end{array}$ & $\begin{array}{l}21-28^{\circ} \mathrm{C} \\
55 \% \& 85 \% \mathrm{RH}\end{array}$ & \\
\hline Viscusi $^{29}$ & 2009 & $\begin{array}{l}0.18-0.20 \\
\mathrm{~mW} / \mathrm{cm}^{2}\end{array}$ & $\begin{array}{l}15 \mathrm{~min} / \\
\text { side }\end{array}$ & $\begin{array}{l}324-360 \\
\mathrm{~mJ} / \mathrm{cm}^{2}\end{array}$ & $3 x$ & $\begin{array}{l}0.97-1.08 \\
\mathrm{~J} / \mathrm{cm}^{2}\end{array}$ & & $40 \mathrm{~W}$ & & $21^{\circ} \mathrm{C}, 50 \% \mathrm{RH}$ & $\begin{array}{l}\text { No observable physical changes, } \\
\text { filtration performance not affected, } \\
\text { no noticeable changes in airflow } \\
\text { resistance }\end{array}$ \\
\hline Bergman $^{36}$ & 2010 & $\begin{array}{l}1.8 \\
\mathrm{~mW} / \mathrm{cm}^{2}\end{array}$ & $15 \mathrm{~min}$ & $1.62 \mathrm{~J} / \mathrm{cm}^{2}$ & $3 \times$ & $\begin{array}{l}4.86 \\
\mathrm{~J} / \mathrm{cm}^{2}\end{array}$ & $25 \mathrm{~cm}$ & $40 \mathrm{~W}$ & & $21^{\circ} \mathrm{C}, 50 \% \mathrm{RH}$ & $\begin{array}{l}\text { No observable physical changes, } \\
\text { no significant change in } \\
\text { penetration }\end{array}$ \\
\hline Heimbuch $^{33}$ & 2011 & $\begin{array}{l}1.6-2.2 \\
\mathrm{~mW} / \mathrm{cm}^{2}\end{array}$ & $15 \mathrm{~min}$ & $\begin{array}{l}1.44-1.98 \\
\mathrm{~J} / \mathrm{cm}^{2}\end{array}$ & $1 \times$ & $\begin{array}{l}1.44-1.98 \\
\mathrm{~J} / \mathrm{cm}^{2}\end{array}$ & $25 \mathrm{~cm}$ & $80 W$ & $>4 \log$ reduction & & $\begin{array}{l}\text { Effective decontamination against } \\
\text { droplet and aerosolized influenza } \\
\text { challenge, no change to fit after } \\
\text { decontamination }\end{array}$ \\
\hline Bergman $^{35}$ & 2011 & $\begin{array}{l}1.6-2.0 \\
\mathrm{~mW} / \mathrm{cm}^{2}\end{array}$ & $15 \mathrm{~min}$ & $\begin{array}{l}1.44-1.98 \\
\mathrm{~J} / \mathrm{cm}^{2}\end{array}$ & $3 \times$ & $\begin{array}{l}4.32-5.94 \\
\mathrm{~J} / \mathrm{cm}^{2}\end{array}$ & & $40 \mathrm{~W}$ & $>4 \log$ reduction & $21^{\circ} \mathrm{C}, 50 \% \mathrm{RH}$ & $\begin{array}{l}\text { Fit not significantly affected after } \\
4 \text { fit tests, no degradation }\end{array}$ \\
\hline Viscusi $^{34}$ & 2011 & $\begin{array}{l}1.6-2.0 \\
\mathrm{~mW} / \mathrm{cm}^{2}\end{array}$ & $\begin{array}{l}15 \mathrm{~min} / \\
\text { side }\end{array}$ & $\begin{array}{l}2.88-3.96 \\
\mathrm{~J} / \mathrm{cm}^{2}\end{array}$ & $1 \times$ & $\begin{array}{l}2.88-3.96 \\
\mathrm{~J} / \mathrm{cm}^{2}\end{array}$ & & $40 \mathrm{~W}$ & & $21^{\circ} \mathrm{C}, 50 \% \mathrm{RH}$ & $\begin{array}{l}\text { No changes in fit, odor detection, } \\
\text { comfort, or donning difficulty with } \\
\text { UVGI- masks were redonned } 5 \times\end{array}$ \\
\hline Lore $^{37}$ & 2012 & $\begin{array}{l}1.6-2.2 \\
\mathrm{~mW} / \mathrm{cm}^{2}\end{array}$ & $15 \mathrm{~min}$ & $\begin{array}{l}1.44-1.98 \\
\mathrm{~J} / \mathrm{cm}^{2}\end{array}$ & $3 \times$ & $\begin{array}{l}4.32-5.94 \\
\mathrm{~J} / \mathrm{cm}^{2}\end{array}$ & $25 \mathrm{~cm}$ & $2 \times 15 W$ & $>4 \log$ reduction & & $\begin{array}{l}\text { Decontamination methods did not } \\
\text { significantly degrade filter } \\
\text { performance at } 300 \mathrm{~nm} \text { particle } \\
\text { size }\end{array}$ \\
\hline Lindsley ${ }^{38}$ & 2015 & & $n / a$ & $\begin{array}{l}120-950 \\
\mathrm{~J} / \mathrm{cm}^{2}\end{array}$ & $1 \times$ & $\begin{array}{l}120-950 \\
\mathrm{~J} / \mathrm{cm}^{2}\end{array}$ & $6.2 \mathrm{~cm}$ & $2 \times 15 W$ & & $27^{\circ} \mathrm{C}, 25 \% \mathrm{RH}$ & $\begin{array}{l}\text { No significance change in flow } \\
\text { resistance, decreased penetration } \\
\text { strength and strap breaking } \\
\text { strength at very high exposure }\end{array}$ \\
\hline Mills $^{11}$ & 2018 & & $60-70 \mathrm{sec}$ & $\begin{array}{l}1.1 \\
\mathrm{~J} / \mathrm{cm}^{2}\end{array}$ & $1 \times$ & $1.1 \mathrm{~J} / \mathrm{cm}^{2}$ & $1 \mathrm{~m}$ & $\begin{array}{l}8 \times 0.39 \\
W / \mathrm{cm}^{2}\end{array}$ & $\begin{array}{l}>3 \text { mean log } \\
\text { reduction, straps } \\
\text { less effectively } \\
\text { decontaminated }\end{array}$ & $21^{\circ} \mathrm{C}, 50 \% \mathrm{RH}$ & $\begin{array}{l}\text { Masks oversaturated with virus in } \\
\text { physiologically relevant solvents } \\
\text { sebum and mucin, ultraviolet } \\
\text { germicidal irradiation levels fully } \\
\text { decontaminated masks, } \\
\text { statistically significant reduction in } \\
\text { virus viability }\end{array}$ \\
\hline Heimbuch $^{12}$ & 2019 & $\begin{array}{l}16-18 \\
\mathrm{~mW} / \mathrm{cm}^{2}\end{array}$ & $60-70 \mathrm{sec}$ & $\begin{array}{l}1.0-1.2 \\
\mathrm{~J} / \mathrm{cm}^{2}\end{array}$ & $20 x$ & $20 \mathrm{~J} / \mathrm{cm}^{2}$ & $1 \mathrm{~m}$ & $\begin{array}{l}8 \times 0.39 \\
W / \mathrm{cm}^{2}\end{array}$ & $\begin{array}{l}>3 \text { mean log } \\
\text { reduction, straps } \\
\text { less effectively } \\
\text { decontaminated, } \\
\text { tested on SARS- } \\
\text { CoV-1 }\end{array}$ & $22.5^{\circ} \mathrm{C}$ & $\begin{array}{l}\text { No meaningfully significant } \\
\text { effect on fit, air flow resistance, or } \\
\text { particle penetration for } 15 \text { models } \\
\text { tested, some models had } \\
\text { significant effects due to donning/ } \\
\text { doffing cycles }\end{array}$ \\
\hline Card $^{42}$ & 2020 & $\begin{array}{l}0.1 \\
\mathrm{~mW} / \mathrm{cm}^{2}\end{array}$ & $\begin{array}{l}20 \mathrm{~min} / \\
\text { side }\end{array}$ & $\begin{array}{l}240 \\
\mathrm{~mJ} / \mathrm{cm}^{2}\end{array}$ & & & $60.6 \mathrm{~cm}$ & $30 \mathrm{~W}$ & & & \\
\hline Lowe $^{9}$ & 2020 & $\begin{array}{l}0.2 \\
\mathrm{~mW} / \mathrm{cm}^{2}\end{array}$ & $5-6 \mathrm{~min}$ & $\begin{array}{l}300 \\
\mathrm{~mJ} / \mathrm{cm}^{2}\end{array}$ & & & $10 \mathrm{ft}$ & $16 x$ & & & \\
\hline
\end{tabular}

Abbreviations: J, Joules; mJ, millijoules; mW, milliwatts; RH, relative humidity; W, watts. 
capsid. UV-C wavelengths (100-280 nm) have the highest decontamination efficiency because the maximum absorption wavelength is $260 \mathrm{~nm}$ and $280 \mathrm{~nm}$ for nucleic acids and proteins, respectively. ${ }^{39}$ Although little is known about the novel SARS-CoV-2, comparisons between SARS-CoV-2 and SARS-CoV-1 can be helpful in estimating conditions in which SARS-CoV-2 may persist. As mentioned, ssRNA viruses, like SARS-CoV-2, are the most susceptible type of virus to UVGI, which is important for understanding the potential success of UVGI treatment. ${ }^{10}$ SARS-CoV-2 can persist on plastic and stainless steel for up to 3 days, although at 72 hours virus titer had decreased 3-fold, and no viable SARS-CoV-2 was measured on cardboard after 24 hours. ${ }^{40}$ How long this virus can remain viable on PPE has yet to be studied and is likely a function of room humidity, contaminating fluids, mask materials, and construction. Because FFRs from different countries of origin use the same polypropylene material to create the mask filter, it is expected that UVGI would perform similarly on the various FFRs. As the following section details, the correct wavelength range is important for the treatment system and must be validated using a UV-C meter to ensure effective dosing in each setup.

\section{PROPOSED SOLUTION: INEXPENSIVE, SCALABLE, AND ACCESSIBLE UVGI SYSTEM FOR FFR DECONTAMINATION}

We propose a collaboration between public and private research institutions and health care facilities to increase the access to UVGI decontamination. Currently, UV-C bulbs required for UVGI are in limited supply; however, most laboratory biosafety cabinets (BSCs) are equipped with UV-C bulbs, and thousands of these bulbs are currently sitting idle, as research has been mainly halted to slow the spread of the virus. Additionally, many research institutions recommend other chemical means of decontamination, thus additionally leaving UV-C bulbs idle. These bulbs also may be available in existing health care facility settings (e.g., tuberculosis wards) where they can be used for decontamination via passive fixtures or air handling units. ${ }^{41}$ Although others have proposed decontaminating FFRs within these BSCs directly, ${ }^{42}$ this requires the masks to be transported to and from the research institutions and staff to run the decontamination cycles. Our approach advances previous work and that from Nebraska
Medicine and allows medical sites to create their own decontamination system, using the idle bulbs, by retrofitting or creating custom light fixtures with off-the-shelf parts available at any retail hardware store.

\section{Building a Mask Decontamination System}

We have developed step-by-step instructions to create UVGI light fixtures that can be downloaded from our website: https://www.gleghornlab.com/ uvgi-decontamination. There are multiple options for fixture assembly, depending on availability of materials, that include:

1. Modifying a premade commercial light fixture to fit new or existing UV-C bulbs:

- Using an existing ceiling light fixture

- Modifying a hanging ceiling fixture

2. Creating a custom fixture from off-the-shelf parts to fit new or existing UV-C bulbs

Because the number and type of bulbs available will vary, we created an easy to follow protocol to create this lamp using almost any common BSC UV-C bulb. The design plans we developed are not limited to BSC UV-C bulbs, and we provide details to adapt them to any UV-C bulbs. The digits printed on a UV-C bulb provide the information necessary to the end user to adapt these bulbs to create these custom UVGI lamps. For example, a bulb labeled "G30T8": G stands for germicidal, 30 is the wattage, and T8 represents the size of the bulbs and pin geometry. For bi-pin bulbs, T5 has a 5/8 inch diameter, T8 has a 1 -inch diameter, and T1 2 has a 1.5-inch diameter. This information is important to match to the correct fixture/bulb holder.

\section{Determining UV-C Exposure Time Required for UVGI Decontamination of FFRs}

Similar studies analyzing the dosages required for proper UVGI decontamination and reuse of FFRs report an optimal UV-C dose of approximately $300 \mathrm{~mJ} / \mathrm{cm}^{2} .9$ To determine UV dosage, design geometries, scalability, and N95 mask decontamination throughput of our designs, we compared a model of irradiation ${ }^{43}$ (measure of UV-C intensity per area) and compared it to measured values of UV-C irradiation from our modified fixture. UV-C intensity on a fixed plane from cylindrical source is nonlinear and is a function of bulb characteristics (length, wattage, radius) and distance to the bulb (Figure 1A). For a single bulb, the highest
To determine UV dosage, optimal design geometry, scalability, and mask decontamination throughput, we measured values of UV-C irradiation from our modified fixture. 
irradiation will be achieved along the midline and will rapidly decay with increasing irradiation width (Figure 1B). We used a UV meter (attenuation $\lambda=254 \mathrm{~nm}$ ) to measure the irradiation area at discrete points using our modified fixture outfitted with a single UV-C bulb (G30T8 with 13.4 W UV output) taken from an existing BSC. The bulb was $88 \mathrm{~cm}$ long and placed $15 \mathrm{~cm}$ above the UV-C meter sensor. We tested areas along the midline and $20 \mathrm{~cm}$ away from the bulb's midline in either

FIGURE 1. (A) Schematic demonstrating the geometric variables that determine ultraviolet germicidal irradiation area. (B) Experimental measurements of ultraviolet intensities are well described by a theoretical model to calculate ultraviolet irradiation. (C) Ultraviolet-C intensities were measured in an irradiation area $88 \mathrm{~cm} \times$ $40 \mathrm{~cm}$ and the midline was $15 \mathrm{~cm}$ from the bulb source. As expected, ultraviolet intensities decay with increasing distance from the bulb, with the lowest intensities measured at the corners of the array. (D) Cartoon of an example table top ultraviolet germicidal irradiation setup.

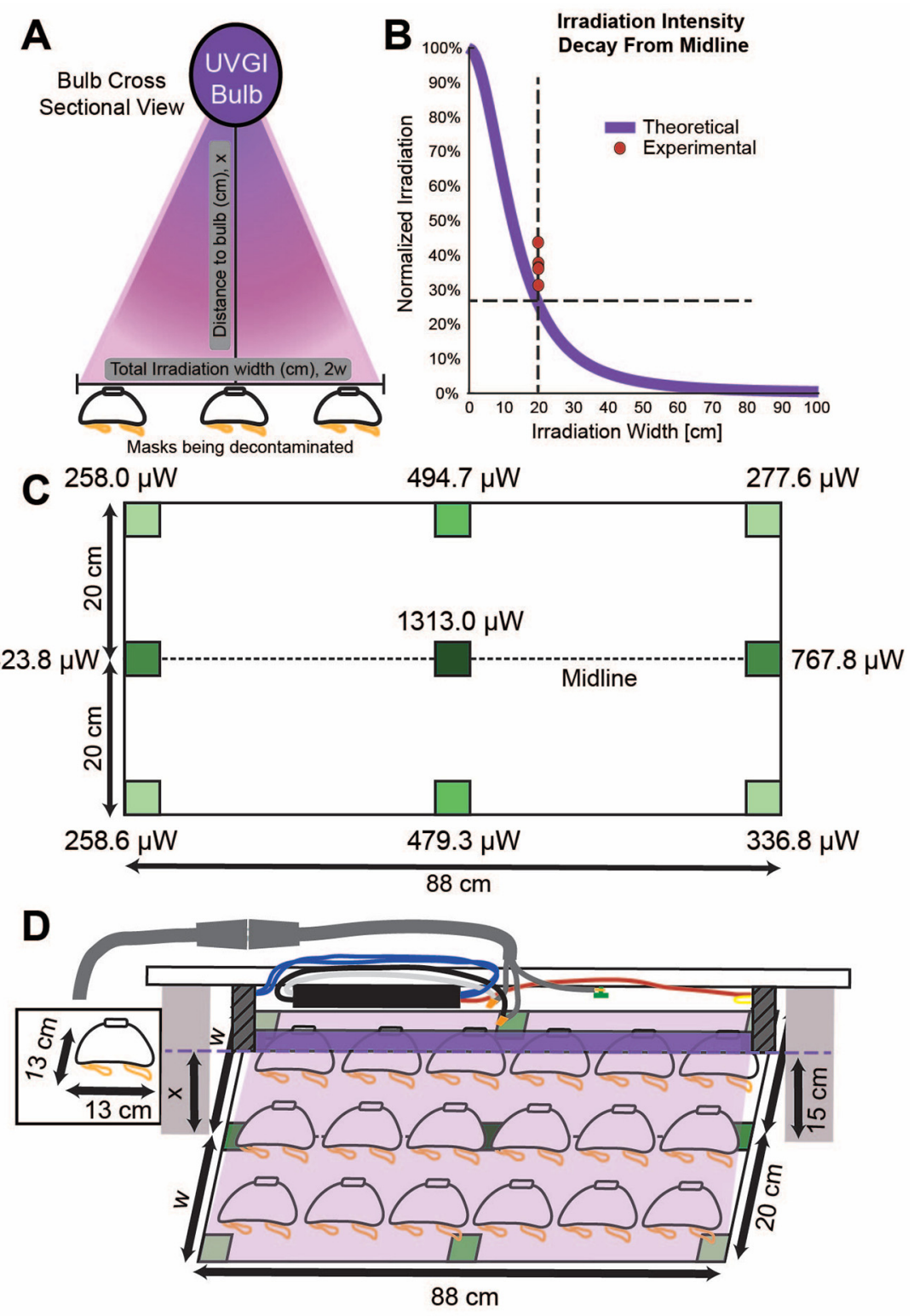


direction, with the sensor flat on the table surface at all locations tested. The highest irradiation was along the midline directly under the bulb and the UV intensities decay, as expected, with increasing irradiation width (Figure 1B, C). Importantly, these measurements demonstrate 2 points. Firstly, the model is a conservative prediction of the intensity distribution, and thus can be used to inform bulb configuration geometries described herein. Secondly, that the bulb intensity is not uniform along its length. Both of these details reinforce the need for user-developed designs and configurations to be validated with UV-C meter measurements to determine the minimum values of UV intensity over the exposure area to calculate exposure times needed in individual configurations.

We measured a new, unused $N 95$ mask (model $7048,3 \mathrm{M}$ ) to be $13 \mathrm{~cm}$ wide, and therefore we could decontaminate an array of $6 \times 3$ masks (Figure 1D). We recommend using a reflective surface such as a stainless steel table or table coated with simple aluminum foil when irradiating on a table surface to maximize irradiation intensities due to reflection.

To calculate the UV-C exposure time, $t$, in seconds, s, needed for treatment, as:

$$
t=\frac{D}{I} \times 1000
$$

where $D$ is the desired dosage value and $I$ is the lowest measured irradiance value from the UV-C meter within the irradiation area.

For an array of $6 \times 3$ masks, using a single bulb, we use the lowest measured UV-C value over the exposure area $\left(258 \mu \mathrm{W} / \mathrm{cm}^{2}\right.$, from Figure $\left.1 \mathrm{C}\right)$ to determine the irradiation time. For our measured setup, the desired dosage (D) is $300 \mathrm{~mJ} / \mathrm{cm}^{2}$ for SARS-CoV- $2^{9}$, irradiance value (I) is $258 \mu \mathrm{W} / \mathrm{cm}^{2}$, and exposure treatment time $(\mathrm{t})$ is 1162.8 seconds or 19.4 minutes for each side of the mask.

$$
t=\frac{300}{258} \times 1000=1162.8
$$

Because the different UV-C bulbs able to be used in this proposed system will have parameters depending on the specifications such as size and age of the bulb, the end user of their own specific UVGI system will need to validate the UV-C values. This should be done using a UV-C meter to determine actual irradiation areas and irradiation times to properly decontaminate the FFRs.

\section{Optimizing UVGI Decontamination Minimize Irradiation Deficits on Mask Surface}

It is important to note that masks placed too close together can create shadows that prevent effective UV decontamination. Additionally, when irradiating masks on a table surface without reflective surfaces, the dome shape of the masks inherently makes it difficult to decontaminate the surfaces on the far side of the mask relative to the position of the light source (Figure 2A, B). To combat this issue, we devised 2 solutions: (1) place a reflective "backboard" at the edge of the array, and (2) place a reflective wedge underneath the mask on the edge of the array to angle the masks toward the light source. A simple wall made of aluminum foil covered cardboard was placed at the edge of the irradiation area (Figure 2C, D). The UV light was able to be reflected off this surface to achieve greater irradiation on the far surfaces of the mask. Using this method, UV-C intensity measured on the mask surface was $63 \%$ of the intensity measured on the front mask surface. In the second approach, a reflective wedge was created by wrapping aluminum foil around a folded piece of cardboard (Figure 2E, F). This sloped surface decreases the effect of the domed shape of the mask by orienting the mask in the direction of the light source to decrease distance from the bulb and prevent shadows caused by the mask surface relative to the bulb position. Using this method, edge region intensities were $79 \%$ that of the measured intensities on the front surface of the mask. However, this modification, in general, places the mask closer to the light source, increasing the overall irradiation intensity by $298 \%$. Such solutions are simple and important to reduce shadows from occurring. Calculated exposure times should be based on the lowest irradiation value at the edge of the irradiation area as measured on the edge of the mask.

\section{Reduce Distance to Fixture}

If we reduce the distance to the bulb, the measured irradiation on the masks will increase nonlinearly and will reduce the time needed to achieve a dose of $300 \mathrm{~mJ} / \mathrm{cm}^{2}$ per side of the mask. Further increases in mask decontamination throughput could be achieved by adding a second light fixture which will allow exposure to both sides of the mask simultaneously, similar to the Nebraska Medicine configuration, reducing the total time for irradiation in half (Figure 2G, H). 
FIGURE 2. Multiple configurations can improve irradiation on the mask surface. (A) Image showing the table top setup of our custom ultraviolet germicidal irradiation. White circles on the table top demonstrate the foot print for placement of masks to be decontaminated within an $88 \mathrm{~cm} \times 40 \mathrm{~cm}$ irradiation area. A shadow is visible on the far surface of the mask (white arrow) indicating decreased exposure due to the curvature of the mask and angle of the ultraviolet rays. (B) The far surface of the mask on the outer rows of our irradiation area, the mask region furthest from the bulb, receives $15 \%$ of the ultraviolet intensity compared to the top of the mask. (C, D) By adding a reflective backboard of aluminum foil wrapped cardboard to the edge of the irradiation area, the ultraviolet rays can be reflected to increase the irradiation exposure to the far surface of the mask. (E, F) Alternatively, by creating a sloped surface for the masks at the edge of the array, mask surfaces can be more aligned toward the light source resulting in more uniform irradiation intensities across the surface. $(\mathbf{G}, \mathbf{H})$ Another decontamination setup includes suspending or hanging the masks. If there is access to a second, optional fixture, this allows for irradiation of both sides of the mask simultaneously.
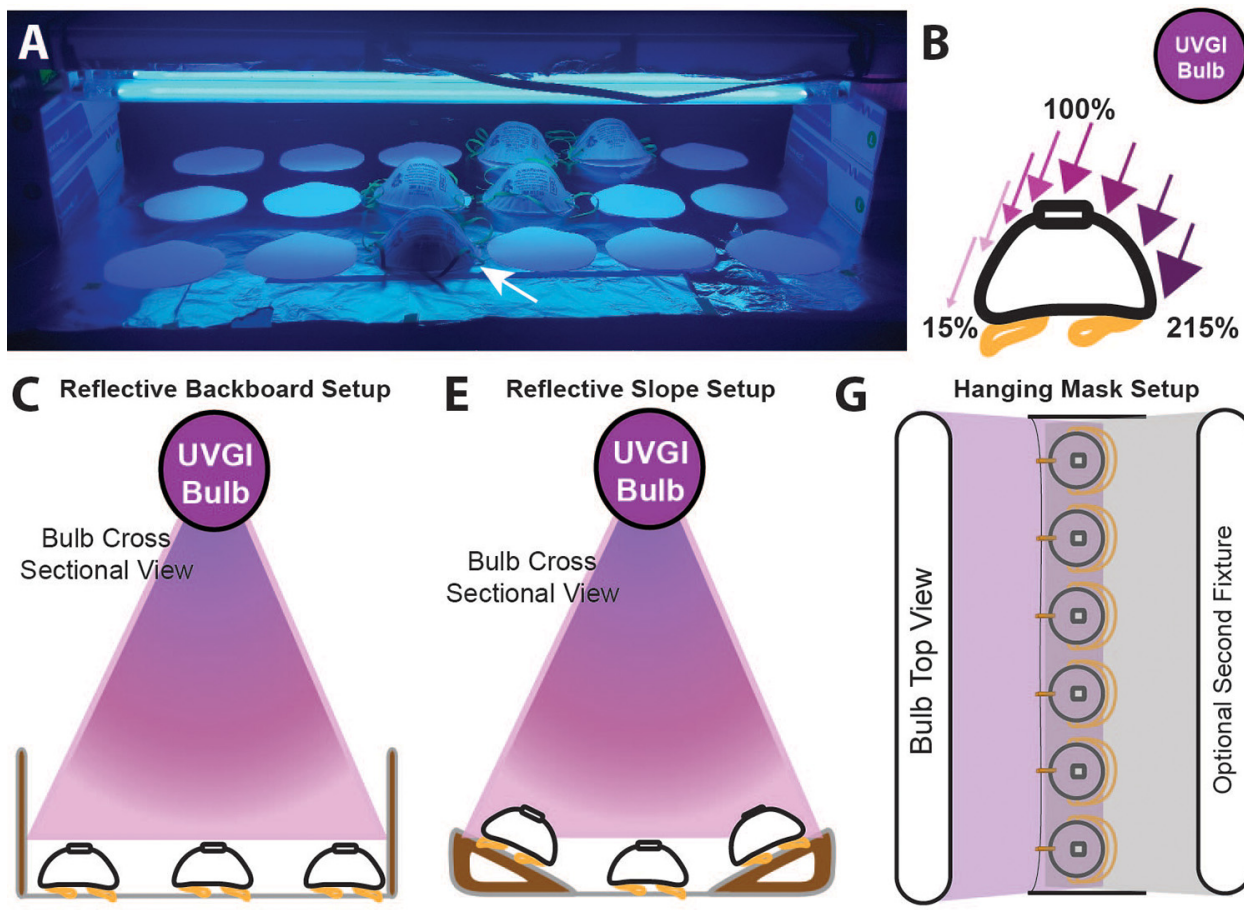

E Reflective Slope Setup

G Hanging Mask Setup
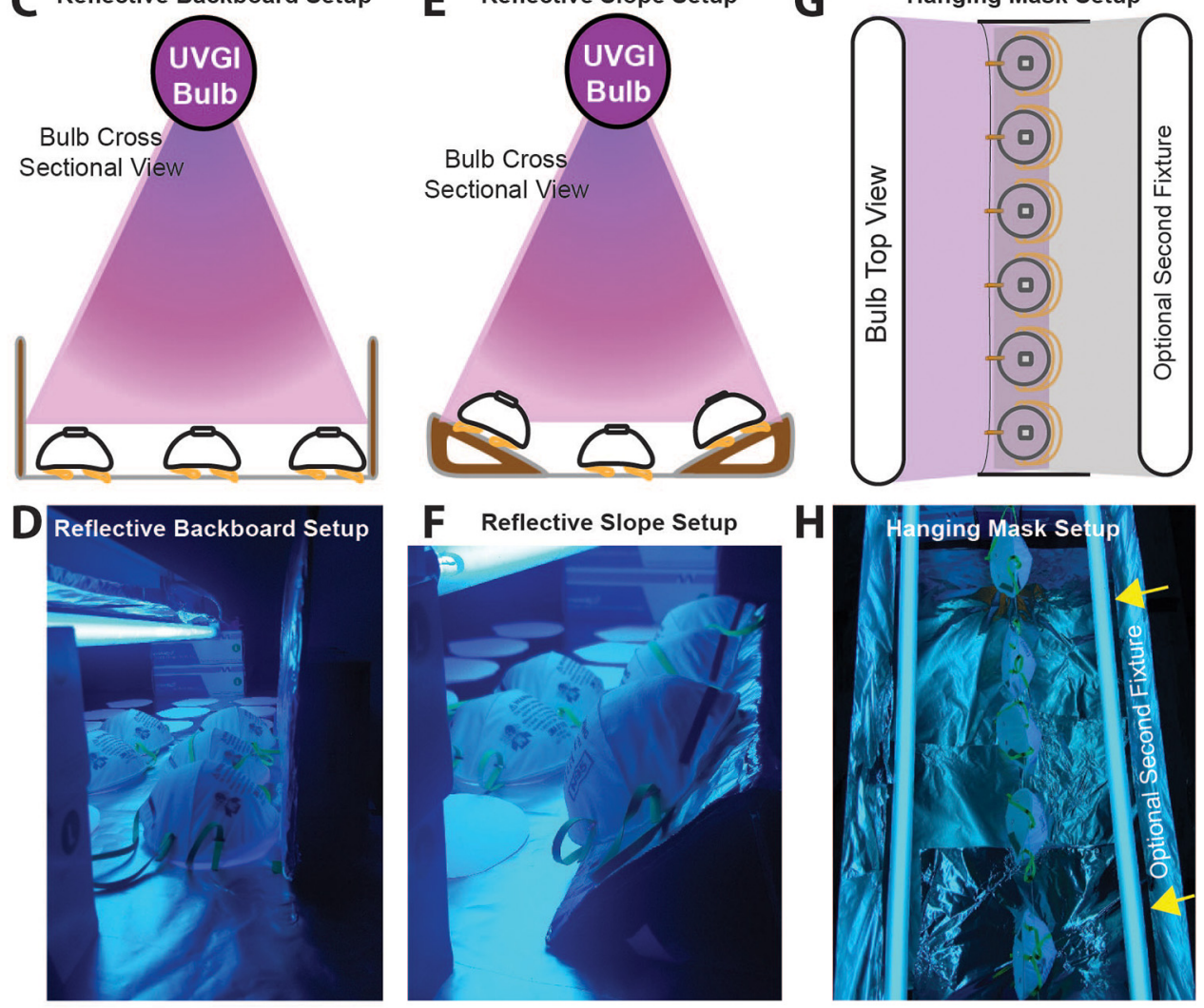


\section{Add Additional Fixtures}

Additional light fixtures can also be placed in parallel to increase the total irradiation area. If placed in close enough proximity, the 2 light fixtures will create an irradiation overlap region which will increase the irradiation intensity to reduce the time needed to decontaminate (Figure 3A). By modeling the theoretical irradiation curves following thermal radiation view factors, ${ }^{43}$ we can determine the effects of adjusting the bulb spacing on the mask decontamination throughput capacity. The $100 \%$ irradiation value used in our model was delegated as the highest measured UV-C intensity that occurred in the center of the array (Figure 1C). For our single bulb setup, using an irradiation width of $20 \mathrm{~cm}$, processing 18 masks in an array, the decontamination time is $19.4 \mathrm{~min}$ utes per side, and thus can decontaminate 27.9 masks/hour (Figure 3B). This time is determined by the lowest intensity measured in our array where the intensity is approximately $26 \%$ that at the midline. However, if we use a modified commercial light fixture outfitted with 2 UV bulbs, the bulbs are closely spaced resulting in high overlap in UV light and the peak intensity of UV is notably increased (Figure 3C, D). This geometry can either produce a larger irradiation width for the same exposure time from $20 \mathrm{~cm}$ to $29 \mathrm{~cm}$ to increase mask throughput (Figure 3C), or we can keep the irradiation width the same and yield a higher UV intensity (Figure 3D). A higher UV intensity decreases the exposure time required and increases mask throughput. Although counterintuitive, Figure 3D demonstrates highest mask throughput (59.6 masks/hour compared to 37.2 masks/hour) by keeping the irradiation field constant (i.e., fewer masks at once) and having a higher UV intensity to decrease exposure time. These measurements and calculations are for a single modified, existing, commercial 2-bulb light fixture.

Although having 2 bulbs in a commercial fixture increases throughput compared to 1 bulb, taking advantage of off-the-shelf components to build a custom fixture has significant advantages. Specifically, users can optimize bulb spacing to increase the uniformity of the irradiation field. If 2 bulbs are spaced at the $50 \%$ irradiation width intensity for 1 bulb, the UV intensities are additive, which creates a more constant irradiation field (Figure 3E, F). Using this configuration, the irradiation width is considerably increased from $20 \mathrm{~cm}$ to $34.5 \mathrm{~cm}$ for a mask exposure time of $19.4 \mathrm{~min}$ utes/side. This generates a mask decontamination throughput of 46.4 masks/hour (Figure 3E). However, similar to findings from the off-the-shelf fixture, keeping the irradiation area constant to take advantage of the higher UV intensities will increase mask throughput more substantially. This approach reduces decontamination time to 5.9 minutes/side and yields a throughput of 91.3 masks/hour for a system with lights only on 1 side of the masks (Figure 3F). This represents a greater than 3 -fold increase in mask processing from 1 UVGI bulb. If a system is created with simultaneous exposure to front and back sides of the masks, using 2 UVGI bulbs on each side, a user could process 182.6 masks/hour. Choosing an optimal setup will all depend on the resources at hand, such as fixtures, bulbs, and treatment environments. The end user will need to validate the UV-C values, using a proper UV-C meter, once the desired configurations of UVGI bulbs are in place to determine actual irradiation areas and irradiation times to properly decontaminate the FFRs. A significant advantage of this system is the potential for parallelization of numerous UVGI light fixtures to simply scale the N95 mask treatment throughput.

\section{Approximate UVGI Fixture Assembly Costs}

This system leverages affordable components and resources already available and distributed across the country in a variety of different research centers. Using our approach to modify commercial fixtures from the hardware store, 1-bulb, 2-bulb, and 4-bulb UVGI light fixtures can each be constructed for less than US\$25, US\$30, and US\$45, respectively. Each custom built fixture (Figure $4 \mathrm{~A}, \mathrm{~B})$ can be constructed for less than US\$21 for a 2-bulb configuration and less than US\$36 for a 4-bulb configuration. These costs do not include the cost of the bulb itself which we believe could be obtained by leveraging collaborations with research institutions to use UV-C bulbs that might otherwise be sitting idle. To implement this UVGI light source, a UV-C meter should be used to provide an accurate measurement of irradiance $(\mu \mathrm{W} /$ $\mathrm{cm}^{2}$ ) at the position of the FFRs will be placed away from the UVGI system. ${ }^{4,23}$ We recommend using a similar workflow and arrangement that Nebraska Medicine developed with their UVGI light towers. Both modified light fixtures or custom fixtures can be easily propped over the decontamination surface by simply resting on boxes (Figure 2A) or affixed to common items in a medical facility such as under a table or an intravenous pole to allow customization and adaptability of the

\section{Using our approach, UVGI light fixtures can be made for US \$25-US\$45, excluding the cost of the bulb.}


FIGURE 3. Irradiation time can be optimized by placing 2 fixtures in close proximity. (A) The ultraviolet light from both fixtures will overlap to create an irradiation overlap region where the ultraviolet intensities are additive. (B) One bulb will create a single maximum irradiation peak; varying the distance between 2 bulbs creates different irradiation and decontamination scenarios which can be modeled to find the optimal conditions. (C), D) Two bulbs modeled in very close proximity; or (E, F) modeled at an optimal distance can increase the irradiation area if the irradiation time is fixed or decrease the irradiation time by increasing the overall exposure within the original irradiation area.
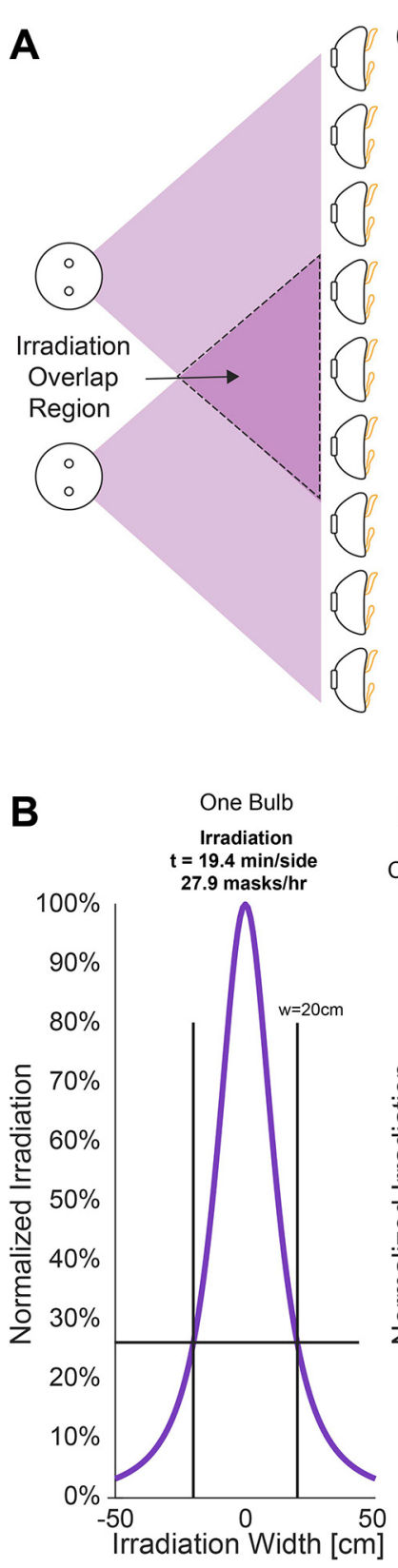

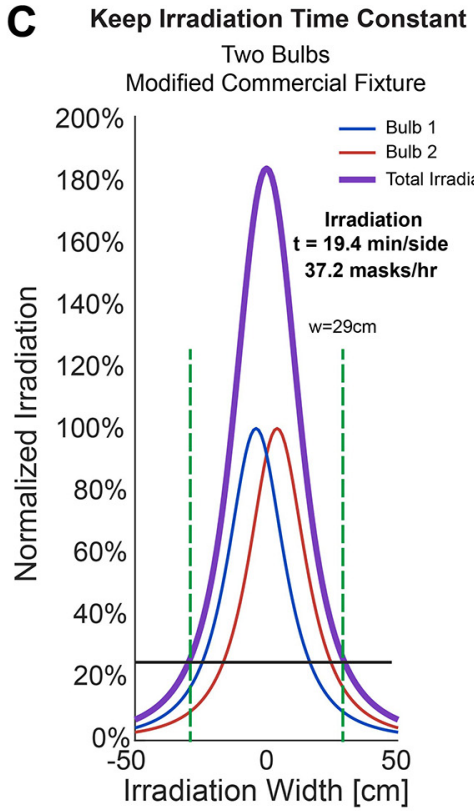

E Keep Irradiation Time Constant Custom Fixture - 50\% Irradiation Distance

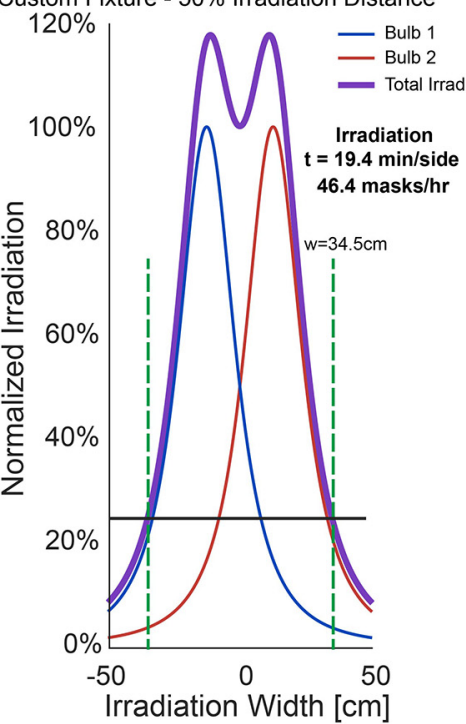

D Keep Irradiation Width Constant Two Bulbs Modified Commercial Fixture

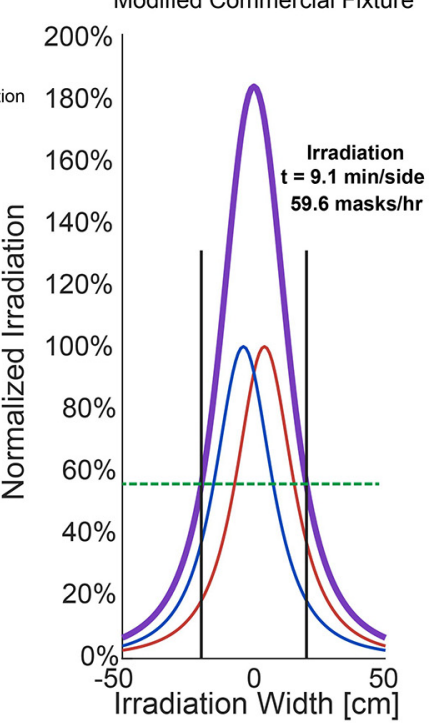

F Keep Irradiation Width Constant Two Bulbs

Custom Fixture - $50 \%$ Irradiation Distance

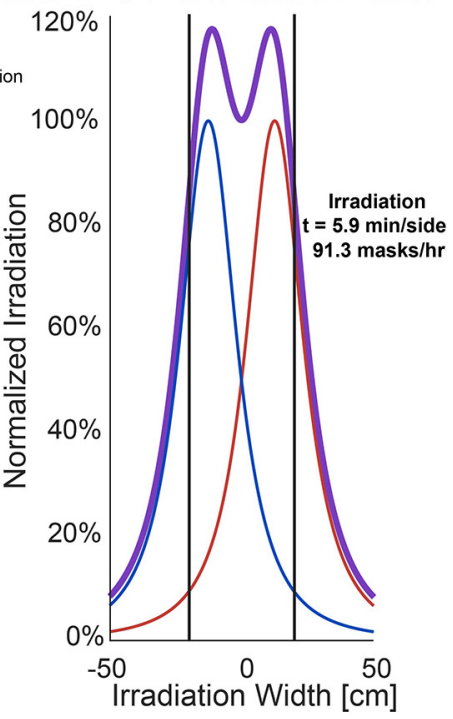


FIGURE 4. An easy, affordable, custom ultraviolet germicidal irradiation system can be built with off the shelf parts. (A) Cartoon representation of our custom built ultraviolet germicidal irradiation fixture. (B) Finished product of our custom ultraviolet germicidal irradiation fixture. (C) Fixtures can be placed over tables or placed vertically by attaching it to health care equipment such as an intravenous pole. (D) Example arrays showing how a user might assemble a horizontal mask decontamination surface or a vertical surface which would allow for irradiation on both sides of the mask pending the availability of additional ultraviolet germicidal irradiation bulbs.

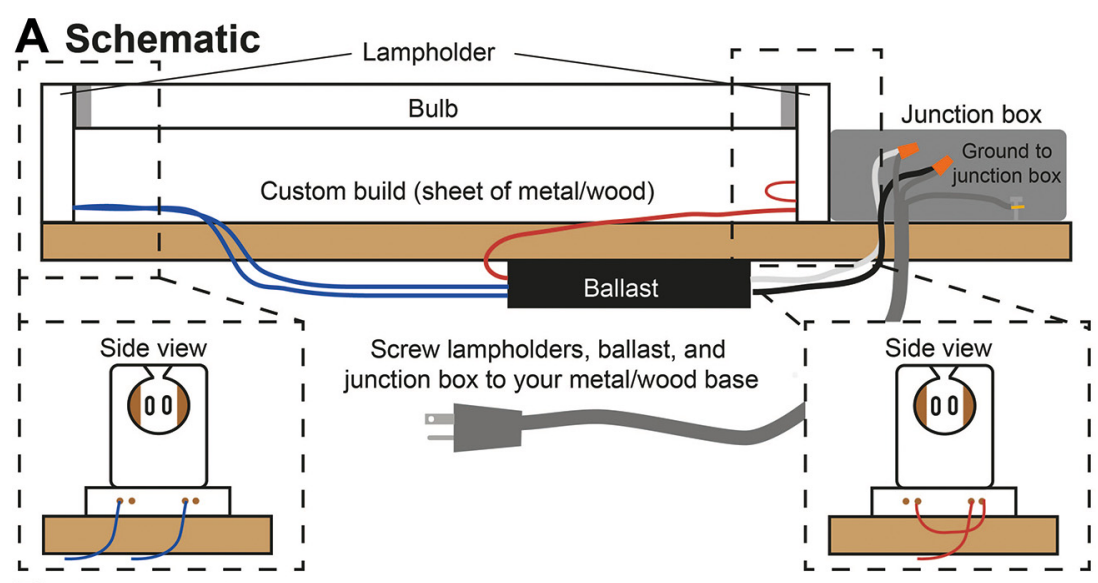

\section{B Finished Product}
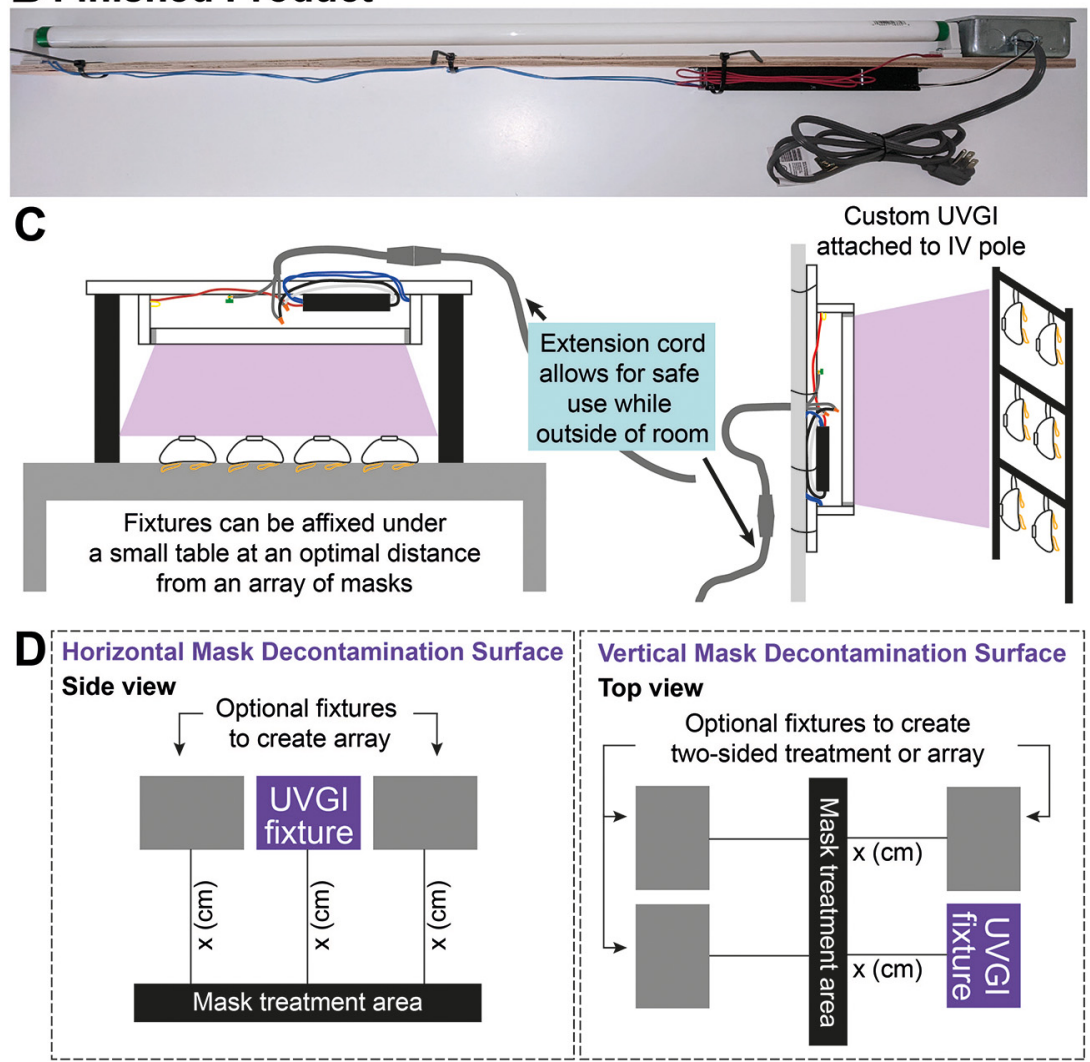
decontamination area (Figure 4C). The end user can also adapt the system to decontaminate masks on a horizontal surface and irradiate only 1 side of the mask at a time (Figure 2A, C-F, Figure 4D) or can suspend the masks to create a vertical decontamination system that will allow for decontamination of both sides of the masks simultaneously (Figure 2G, H, 4D). Using these modified light sources adds significant flexibility in the positioning of UV-C systems to generate multiple largerscale UVGI bulb arrays or several treatment systems in parallel.

\section{CONCLUSION}

Our system leverages a collaboration between research institutions and health care facilities, but otherwise has minimal associated cost and expertise. Research institutions can donate UVGI bulbs; UV PPE, including goggles and face shields; and the necessary UV-C meter. Health care facilities can assemble the UVGI systems and implement a decontamination protocol such as that established by Nebraska Medicine as an excellent starting point. ${ }^{9}$ Our website (https://gleghornlab.com/ uvgi-decontamination) provides the step-by-step downloadable plans to create the UVGI system, as well as helpful graphics to assist end users to determine their required decontamination times based on the measured UV-C output $(\lambda=254 \mathrm{~nm})$ at a defined distance. When working with our proposed UVGI system, it is also important to use proper UV safety procedures, including avoiding any direct eye or skin exposure to the UV light source.

Whereas these instructions are illustrated using materials available in the United States, this concept has global application. The same bulbs are used in research BSCs, medical settings, and increasingly, water treatment and food safety applications throughout the world. The ability for HCWs to quickly decontaminate PPE on site during any health care emergency could be an important measure to reduce the spread of infectious diseases, especially when time and other resources are limited.

Funding: Although this specific project was not directly funded by specific grants, we would like to thank the funding agencies of our other projects including the National Institutes of Health, the National Science Foundation, and the Bernard Canavan Award.

Competing interests: None declared.

\section{REFERENCES}

1. Centers for Disease Control and Prevention. Decontamination and reuse of filtering facepiece respirators. Updated April 30, 2020. Accessed August 13, 2020. https://www.cdc.gov/coronavirus/ 2019-ncov/hcp/ppe-strategy/decontamination-reuse-respirators. $\mathrm{html}$

2. Coronavirus (COVID-19) update: FDA issues second emergency use authorization to decontaminate $\mathrm{N} 95$ respirators. News release.
Food \& Drug Administration; April 10, 2020. Accessed August 13, 2020. https://www.fda.gov/news-events/press-announcements/ coronavirus-covid-19-update-fda-issues-second-emergency-useauthorization-decontaminate-n95

3. Coronavirus (COVID-19) update: FDA issues emergency use authorization to decontaminate millions of N95 respirators. News release. Food \& Drug Administration; April 12, 2020. https://www. fda.gov/news-events/press-announcements/coronavirus-covid-19update-fda-issues-emergency-use-authorization-decontaminatemillions-n95

4. Padilla M. 'It feels like a war zone': doctors and nurses plead for masks on social media. New York Times. March 19, 2020. Accessed August 13, 2020. https://www.nytimes.com/2020/03/19/us/ hospitals-coronavirus-ppe-shortage.html

5. Goodnough A. Some hospitals are close to running out of crucial masks for coronavirus. New York Times. March 9, 2020. Accessed August 13, 2020. https://www.nytimes.com/2020/03/09/ health/coronavirus-n95-face-masks.html

6. Nierenberg A. Where are all the masks? New York Times. April 3, 2020. Accessed August 13, 2020. https://www.nytimes.com/ article/face-masks-coronavirus.html

7. Wan W. America is running short on masks, gowns and gloves. Again. Washington Post. July 8, 2020. Accessed August 13, 2020. https://www.washingtonpost.com/health/2020/07/08/ppeshortage-masks-gloves-gowns/

8. Farber M. N95 shortage has Minnesota health care workers reusing these protective respirators: It's 'disgusting.' Fox News. June 30, 2020. Accessed August 13, 2020. https://www.foxnews.com/ health/n95-shortage-minnesota-health-care-workers-reuse

9. Lowe JJ, Paladino KD, Farke JD, et al. N95 Filtering Facepiece Respirator Ultraviolet Germicidal Irradiation (UVGI) Process for Decontamination and Reuse. Nebraska Medicine; 2020. Accessed August 13, 2020. https://www.nebraskamed.com/sites/default/ files/documents/covid-19/n-95-decon-process.pdf

10. Tseng CC, Li CS. Inactivation of viruses on surfaces by ultraviolet germicidal irradiation. J Occup Environ Hyg. 2007;4(6):400-405. CrossRef. Medline

11. Mills D, Harnish DA, Lawrence C, Sandoval-Powers M, Heimbuch BK. Ultraviolet germicidal irradiation of influenza-contaminated N95 filtering facepiece respirators. Am J Infect Control. 2018;46(7): e49-55. CrossRef. Medline

12. Heimbuch B, Harnish D. Research to Mitigate a Shortage of Respiratory Protection Devices During Public Health Emergencies. Final Report. Applied Research Associates; 2019. Accessed August 13, 2020. https://www.ara.com/sites/default/files/Mitigate ShortageofRespiratoryProtectionDevices_3.pdf

13. American Hospital Association. Fast facts on U.S. hospitals, 2020. Health Forum; 2020. Accessed August 13, 2020. https://www.aha. org/statistics/fast-facts-us-hospitals

14. Center for Sustainable Systems, University of Michigan. U.S. cities factsheet. Center for Sustainable Systems, University of Michigan; 2019. Accessed August 13, 2020. http://css.umich.edu/ factsheets/us-cities-factsheet

15. Republic of Kenya, Ministry of Health. Kenya master health facility list. Accessed August 13, 2020. http://kmhfl.health.go.ke/\#/home

16. World Health Organization (WHO). Primary Health Care Systems (PRIMASYS): Comprehensive Case Study From Kenya. WHO; 2017. Accessed August 13, 2020. https://www.who.int/alliance-hpsr/ projects/Alliance-PRIMASYS-Kenya-comprehensive.pdf

17. Oketch A. Cloth masks don't guarantee protection, says State. Daily Nation. May 13, 2020. Accessed August 13, 2020. https://www. nation.co.ke/news/Cloth-masks-don-t-guarantee-protection-saysState-/1056-5519994-3p06df/index.html 
18. Mother and Newborn Information for Tracking Outcomes and Results (MoNITOR). Medical doctors (per 10000 population). World Health Organization. Accessed August 13, 2020. https://www. who.int/data/maternal-newborn-child-adolescent/monitor

19. Dalal N. Africa cannot afford to lose doctors to COVID-19. World Economic Forum. April 9, 2020. Accessed August 13, 2020. https://www.weforum.org/agenda/2020/04/africa-cannot-losedoctors-covid-19/

20. Saslow E. 'Out here, it's just me': in the medical desert of rural America, one doctor for 11,000 square miles. Washington Post. September 28, 2019. Accessed August 13, 2020. https://www. washingtonpost.com/national/out-here-its-just-me/2019/09/28/ faldf9b6-deef-1 le9-be96-6adb81821 e90_story.html

21. Mandavilli A. Medical workers should use respirator masks, not surgical masks. New York Times. June 1, 2020. Accessed August 13, 2020. https://www.nytimes.com/2020/06/01/health/maskssurgical-N95-coronavirus.html

22. Carlson J. Still in short supply, N95 masks are being used over and over. Concord Monitor. June 29, 2020. Accessed August 13, 2020. hitps://www.concordmonitor.com/Still-in-short-supply-N95masks-are-being-used-over-and-over-35000192

23. Kates G. N95 mask shortage comes down to this key material: "the supply chain has gotten nuts." CBS News. April 9, 2020. Accessed August 13, 2020. https://www.cbsnews.com/news/n95-maskshortage-melt-blown-filters/

24. Institute of Medicine. Reusability of Facemasks During an Influenza Pandemic: Facing the Flu. The National Academies Press; 2006. CrossRef

25. Carias $C$, Rainisch $G$, Shankar $M$, et al. Potential demand for respirators and surgical masks during a hypothetical influenza pandemic in the United States. Clin Infect Dis. 2015;60 Suppl 1 (Suppl_1):S42-S51. CrossRef. Medline

26. 3M. Comparison of FFP2, KN95, and N95 and Other Filtering Facepiece Respirator Classes. 3M; 2020. Accessed August 13 2020. https://multimedia.3m.com/mws/media/17915000/ comparison-ffp2-kn95-n95-filtering-facepiece-respirator-classes-tb. pdf

27. Blachere FM, Lindsley WG, McMillen CM, et al. Assessment of influenza virus exposure and recovery from contaminated surgical masks and N95 respirators. J Virol Methods. 2018;260:98-106. CrossRef. Medline

28. Centers for Disease Control and Prevention. Implementing filtering facepiece respirator (FFR) reuse, including reuse after decontamination, when there are known shortages of N95 respirators. Updated August 4, 2020. Accessed August 13, 2020. hitps://mww.cdc.gov/coronavirus/ 2019-ncov/hcp/ppe-strategy/decontamination-reuse-respirators.html

29. Viscusi DJ, Bergman MS, Eimer BC, Shaffer RE. Evaluation of five decontamination methods for filtering facepiece respirators. Ann Occup Hyg. 2009;53(8):815-827. CrossRef. Medline

30. Halperin E. Battelle cleared to sterilize N95 masks at max capacity, operate in other states to fight coronavirus PPE shortage. NBC4 WCMH-TV. March 29, 2020. Accessed August 13, 2020. https:// www.nbc4i.com/community/health/coronavirus/gov-dewine-fdalimits-battelles-ppe-mask-sterilizing-technology-to-only-10k-a-day/

31. Keeping the human connection in drug delivery device development. Battelle Insider blog. February 27, 2020. Accessed August 13, 2020. https://inside.battelle.org/blog-details/keeping-the-humanconnection-in-drug-delivery-device-development

32. Fischer $\mathrm{R}$, Morris DH, Doremalen $\mathrm{N}$ van, et al. Assessment of $\mathrm{N} 95$ respirator decontamination and re-use for SARS-CoV-2. Preprint. Posted online April 15, 2020. medRxiv. CrossRef. Medline

33. Heimbuch BK, Wallace WH, Kinney K, et al. A pandemic influenza preparedness study: use of energetic methods to decontaminate filtering facepiece respirators contaminated with $\mathrm{H} 1 \mathrm{~N} 1$ aerosols and droplets. Am J Infect Control. 2011;39(1):e1-e9. CrossRef. Medline

34. Viscusi DJ, Bergman MS, Novak DA, et al. Impact of three biological decontamination methods on filtering facepiece respirator fit, odor, comfort, and donning ease. J Occup Environ Hyg. 2011 ;8(7):426436. CrossRef. Medline

35. Bergman MS, Viscusi DJ, Palmiero AJ, Powell JB, Shaffer RE. Impact of three cycles of decontamination treatments on filtering facepiece respirator fit. J Int Soc Resp Protection. 201 1;28(1):48-59. Accessed August 13, 2009. https://www.isrp.com/the-isrp-journal/journalpublic-abstracts/1135-vol-28-no-1-2011-pp-48-59-bergmanopen-access

36. Bergman MS, Viscusi DJ, Heimbuch BK, Wander JD, Sambol AR, Shaffer RE. Evaluation of multiple (3-cycle) decontamination processing for filtering facepiece respirators. J Eng Fibers Fabrics. 2010;5 (4):33-41. CrossRef

37. Lore MB, Heimbuch BK, Brown TL, Wander JD, Hinrichs SH. Effectiveness of three decontamination treatments against influenza virus applied to filtering facepiece respirators. Ann Occup Hyg. 2012;56(1):92-101. CrossRef. Medline

38. Lindsley WG, Martin SB, Thewlis RE. Effects of ultraviolet germicidal irradiation (UVGI) on N95 respirator filtration performance and structural integrity. J Occup Environ Hyg. 2015;12(8):509-17. CrossRef. Medline

39. Anderson JG, Rowan NJ, MacGregor SJ, Fouracre RA, Farish O. Inactivation of food-borne enteropathogenic bacteria and spoilage fungi using pulsed-light. IEEE Transactions Plasma Sci. 2000;28 (1):83-88. CrossRef

40. van Doremalen N, Bushmaker T, Morris DH, et al. Aerosol and surface stability of SARS-CoV-2 as compared with SARS-CoV-1. NEngl J Med. 2020;382(16):1564-1567. CrossRef. Medline

41. Mamahlodi MT. Potential benefits and harms of the use of UV radiation in transmission of tuberculosis in South African health facilities. $J$ Public Health Afr. 2019;10(1):742. CrossRef. Medline

42. Card KJ, Crozier D, Dhawan A, et al. UV sterilization of personal protective equipment with idle laboratory biosafety cabinets during the COVID-19 pandemic. Preprint. Posted online April 15, 2020. medRxiv. CrossRef

43. Kowalski W. Ultraviolet Germicidal Irradiation Handbook. Springer International Publishing; 2009.

\section{Peer Reviewed}

Received: May 12, 2020; Accepted: August 11, 2020; First published online: September 11, 2020

Cite this article as: Gilbert RM, Donzanti MJ, Minahan DJ, et al. Mask reuse in the COVID-19 pandemic: creating an inexpensive and scalable ultraviolet system for filtering facepiece respirator decontamination. Glob Health Sci Pract. 2020;8(3):582-595. https://doi.org/10.9745/GHSP-D-2000218

(c) Gilbert et al. This is an open-access article distributed under the terms of the Creative Commons Attribution 4.0 International License (CC BY 4.0), which permits unrestricted use, distribution, and reproduction in any medium, provided the original author and source are properly cited. To view a copy of the license, visit http:// creativecommons.org/licenses/by/4.0/. When linking to this article, please use the following permanent link: https:// doi.org/10.9745/GHSP-D-20-00218 